\title{
Coronary Artery disease prevalence in Patients having essential hypertension with or without Diabetes Mellitus Detected by Cardiac MIBI Scan
}

\author{
Owais Bin Qadeer Gill a, Talal Abdul Rehman ${ }^{\text {b }}$ Hafiz Amjad Hussainc, Muhammed Shahzad Afzal ${ }^{\mathrm{d}}$ \\ aPrincipal Radiologist, PINUM Cancer Hospital, Faisalabad.

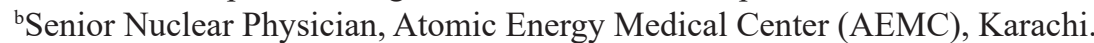 \\ ${ }^{c}$ Assistant Professor, Department of Medicine, Faisalabad Medical University, Faisalabad. \\ ${ }^{\mathrm{d} D C M O}$, Head Nuclear Medicine, PINUM Cancer Hospital, Faisalabad. \\ *Corresponding Author's e-mail:_drowaisgill@gmail.com
}

\section{ABSTRACT}

BACKGROUND \& OBJECTIVE: The aim of this retrospective study was to find the prevalence of coronary artery disease (CAD) in hypertensive patients with or without diabetes mellitus.

METHODOLOGY: Data of patients having essential hypertension ( $n=931$ ) referred to PINUM from April 2017 to December 2018 for stress/rest cardiac MIBI scan was analyzed. This data was divided into two groups. HD group contains data of patients having hypertension with diabetes mellitus $(n=456,48.98 \%$ of total population, $M: F=245: 211)$. While data of patients having hypertension without diabetes mellitus was placed in $\mathrm{H}$ group $(\mathrm{n}=475,51.02 \%$ of total population, M: $\mathrm{F}=254: 221$ ).

RESULTS: Prevalence of CAD is higher in HD group than in H group (47.8\% vs. 30.1\%; $<<0.001$ ). CAD is more prevalent in males than females in both groups (53.9 \% vs. $40.8 \%$ in HD group, and $39.4 \%$ vs. $19.5 \%$ in $\mathrm{H}$ group). This difference in prevalence of CAD in HD and $\mathrm{H}$ groups is more marked in females $(40.8 \%$ vs. $19.5 \%$; $<<0.001)$ than males $(53.9 \%$ vs. $39.4 \% ; \mathrm{p}=0.001)$. Prevalence of CAD in patients with typical presentation is not statistically significant in HD and $\mathrm{H}$ groups $(72.3 \%$ vs. $68.4 \% ; \mathrm{p}=0.645)$, while in subjects with atypical presentation prevalence is significantly higher in HD group than H group (40.8\% vs. $26.8 \%$; $<<0.001)$.

CONCLUSION: Prevalence of CAD is higher in the group of patients having essential hypertension with diabetes mellitus than the group of patients having essential hypertension without diabetes mellitus.

KEYWORDS: Coronary artery disease, Hypertensive, Diabetes mellitus.

\section{INTRODUCTION}

Cardiac MIBI scan is a widely used technique of nuclear medicine employed to non-invasively assess status of myocardial perfusion. It can be used as a gateway for screening patients going to cath-lab for percutaneous transluminal coronary angiography (PTCA). MPS is satisfactorily sensitive, cost effective and non-invasive and gives adequate information about cardiac perfusion abnormalities ${ }^{[1]}$. It has an edge of identifying perfusion defects due to microangiopathies, that can occur in multitude of diseases, especially essential hypertension and diabetes mellitus ${ }^{[2]}$.

The burden of essential hypertension and diabetes mellitus is increasing day by day due to increasing consumption of a highly refined diet, sedentary lifestyle and multiple other risk factors. These in turn lead to a high incidence and prevalence of coronary artery disease (CAD) all over the world causing substantial morbidity, mortality and economic burden.

Essential hypertension and diabetes mellitus are known strong risk factors for CAD. It is widely observed and reported that the concomitant presence of these two risk factors substantially increases the chances of CAD. Information about status of myocardial perfusion in such a population will be highly helpful to ascertain prevalence of $\mathrm{CAD}^{[3]}$. This in turn would lead to judicious and costeffective use of resources with better, long term patient management ${ }^{[4]}$. Little work is done using MPS for screening such a high-risk population. Cardiac catheterization, which is the gold standard for CAD diagnosis, cannot be frequently

Gill Qadeer OB, Rehman TA, Iqbal M, Afzal MS. Coronary Artery Disease Prevalence in Patients Having Essential Hypertension with Or Without Diabetes Mellitus Detected Cardiac MIBI Scan. Journal of University Medical \& Dental College. 2022; 13(1):334-339. 
used due to its invasive nature, in a large number of patients just to find prevalence of CAD ${ }^{[5]}$.

In this retrospective study, prevalence of CAD was determined in patients having essential hypertension, with or without diabetes mellitus. Data for this retrospective analysis was collected from hospital records of patients that underwent cardiac MIBI scan at PINUM from April 2017 to December 2018.

\section{METHODOLOGY}

This descriptive, cross-sectional study was done from April 2017 to December 2018 in Punjab Institute of Nuclear Medicine (PINUM), Faisalabad (ERC/2017/4/PINUM). Data of all Hypertensive patients, who were referred to PINUM for cardiac MIBI scan, was included in the study. Data of all non-hypertensive patients who were referred to PINUM for cardiac MIBI scan was excluded from this study. Data of patients with known CAD was also excluded. Standard exclusion criteria for cardiac MIBI scan was also applied. therefore, pregnant and lactating females, patients with unstable angina, patients with hypertrophic obstructive cardiomyopathy (HOCM), cerebrovascular accident (CVA) and aortic stenosis (AS) were not included in the study. This data was divided into two groups; HD group and $\mathrm{H}$ group. HD group contains data of patients having essential hypertension (HTN) with diabetes mellitus (DM). H group consists of data of patients having essential hypertension (HTN) without diabetes mellitus (DM).

Patients included in this study had gone through myocardial perfusion scintigraphy with different radiotracers/ pharmaceuticals, as per availability, according to hospital routine. Radiotracers used were $201 \mathrm{Tl}, 99 \mathrm{mTc}$ labeled MIBI (methoxy-isobutyl-isonitrile) and 99mTc labeled Tetrofosmin (myoview). Kits of MIBI and generator of 99 mTc were supplied by Pakistan Institute of Nuclear Sciences and Technology (PINSTECH) Islamabad. 201 Tl in the form of Thallous Chloride, and cold kits of Tetrofosmin were supplied by GE Health. Patients had gone through stress and rest Cardiac scan on separate days for $99 \mathrm{mTc}$ labeled radiopharmaceuticals. Stress and redistribution studies were done on the same day for 201Tl. Siemens E.CAM gamma camera was used for acquisition of all studies.

Data compilation, prevalence analysis, calculations of mean and standard deviation, etc. in different groups was done with Statistical Package for Social Sciences (SPSS) version 25 . SPSS was also used for $\chi 2$ (Chi-square) test, to determine the statistical significance of the difference observed in the prevalence of CAD in $\mathrm{HD}$ and $\mathrm{H}$ group patients. A value of $\mathrm{p}<0.05$ was taken as statistically significant.

\section{RESULTS}

Data of patients was quite similar regarding gender (male: $49.1 \%$ vs. $50.9 \%$, and female: $48.8 \%$ vs. $51.1 \%$ ) and age (mean $+\mathrm{SD}=52.4+10.2$ vs. $48.7+10.9$ years, range: $27-$ 80 vs. 23-80) in HD and $H$ groups respectively. Average duration of hypertension was $5.2+5.0$ years and $5.6+5.5$ years in $\mathrm{HD}$ and $\mathrm{H}$ groups respectively. Mean duration of diabetes mellitus in HD group was 7.0+5.8 years) (Table-I). Symptoms of presentation varied considerably in $\mathrm{HD}$ and $\mathrm{H}$ groups. Typical chest pain presentation was more common in males than females of HD group $(62.4 \%$ vs. $37.6 \%)$ and $\mathrm{H}$ group $(71.1 \%$ vs. $28.9 \%)$. Among the patients who presented with atypical symptoms, distribution in both genders was almost similar in HD group and $\mathrm{H}$ group (male: $51.3 \%$ vs. $51.9 \%$, Female $48.7 \%$ vs. $48.1 \%$ ).

No risk factor other than HTN or DM was associated in $43.2 \%$ and $54.9 \%$ of the patients in HD and $\mathrm{H}$ groups respectively. History of smoking was found in $13.8 \%$ of HD group and $21.9 \%$ of $\mathrm{H}$ group patients, while family history of CAD was observed in $24.3 \%$ of HD group and $29.3 \%$ of H group subjects (Table-II).

Out of 456 patients in HD group and 475 patients in $\mathrm{H}$ group, prevalence of CAD was almost 1.5 times higher in HD group (47.8\%) than H group (30.1\%) and $\chi 2$ test showed this difference in prevalence of CAD to be statistically significant $(\mathrm{p}=0.0001)$. Out of 238 patients in HD group and 332 patients in $\mathrm{H}$ group, prevalence of ischemia was almost 2 times higher in HD group (31.9\%) than $\mathrm{H}$ group $(18.7 \%), p=0.0001$. Out of 162 patients in HD group and 270 patients in $\mathrm{H}$ group, prevalence of MI was $16 \%$ in HD group and $11.1 \%$ in $\mathrm{H}$ group ( $\mathrm{p}=0.139)$.

Prevalence of CAD was significantly higher in patient who presented with angina as compared to those with atypical presentation in both $\mathrm{HD}$ and $\mathrm{H}$ groups. In HD group patients who presented with typical angina $72.3 \%$ had CAD as compared to patients in $\mathrm{H}$ group $68.4 \%$ had CAD. Application of $\chi 2$ test showed that this difference of prevalence in patients with typical presentation was not statistically significant $(p=0.654)$. However, in HD group patients with atypical presentation $40.8 \%$ had CAD as compared to patients in $\mathrm{H}$ group $26.8 \%$ had CAD, $(\mathrm{p}=0.0001)$.

In HD group patients with typical presentation $46.4 \%$ had ischemia as compared to patients in $\mathrm{H}$ group $33.3 \%$ had ischemia, $(p=0.443)$. However, in HD group patients with atypical presentation $29.5 \%$ had ischemia as compared to patients in $\mathrm{H}$ group $18.4 \%$ had ischemia, $(\mathrm{p}=0.003)$. In

Table-I: Demographic Data of the Study Population.

\begin{tabular}{|c|c|c|c|c|}
\hline \multicolumn{2}{|l|}{ Total (n) } & \multirow{2}{*}{$\frac{\text { HD group }}{456}$} & \multirow{2}{*}{$\begin{array}{c}\text { H group } \\
475\end{array}$} & \multirow{2}{*}{$\begin{array}{l}\text { All } \\
931\end{array}$} \\
\hline & & & & \\
\hline \multirow[t]{2}{*}{ Gender } & Male (n) & 245 & 254 & 499 \\
\hline & Female (n) & 211 & 221 & 432 \\
\hline Age (years) & Mean \pm SD & $52.4 \pm 10.2$ & $48.7 \pm 10.9$ & $\begin{array}{l}50.5 \\
10.7\end{array}$ \\
\hline $\begin{array}{l}\text { Duration of } \\
\text { HTN (years) }\end{array}$ & Mean \pm SD & $5.2 \pm 5.0$ & $5.6 \pm 5.5$ & $\begin{array}{l}5.4 \\
5.2\end{array}$ \\
\hline \multirow[t]{2}{*}{$\begin{array}{l}\text { Duration of } \\
\text { DM (years) }\end{array}$} & Mean \pm SD & $7.0 \pm 5.8$ & $\begin{array}{c}\text { Not } \\
\text { applicable }\end{array}$ & 7.0 \\
\hline & & & $\begin{array}{c}\text { Not } \\
\text { applicable }\end{array}$ & 5.8 \\
\hline
\end{tabular}


HD group patients with typical presentation $33.3 \%$ had MI as compared to patients in $\mathrm{H}$ group $25 \%$ had ischemia, $(\mathrm{p}=0.679)$. However, in HD group patients with atypical presentation $15.5 \%$ had $\mathrm{MI}$ as compared to patients in $\mathrm{H}$ group $10 \%$ had MI, ( $\mathrm{p}=0.095)$.

Prevalence of CAD increases with increasing age in both groups. In HD group, prevalence of CAD was $25 \%$, $44.8 \%, 49.5 \%$ and $64.3 \%$ in patients with age; less than 36 years, 36-50 years, 51-65 years and greater than 65 years respectively. In $\mathrm{H}$ group patients, $\mathrm{CAD}$ was found in $13.2 \%$, $25.7 \%, 40.28 \%$ and $45.5 \%$ subjects with age; less than 36 years, 36-50 years, 51-65 years and greater than 65 years respectively. Prevalence of ischemia and MI behaved with a trend similar to that of $\mathrm{CAD}$, i.e., prevalence increases with increasing age.

Table-II: Associated Risk Factors in HD and H Groups.

\begin{tabular}{ccc}
\hline Risk factors for CAD & HD group & H group \\
\hline No other risk factor & $197(43.2 \%)$ & $261(54.9 \%)$ \\
Smoking & $63(13.8 \%)$ & $104(21.9 \%)$ \\
Family history of CAD & $111(24.3 \%)$ & $139(29.3 \%)$ \\
Hyperlipidemia & $68(15 \%)$ & $44(9.3 \%)$ \\
Obesity & $129(28.3 \%)$ & $131(27.6 \%)$
\end{tabular}

Table-III: Coronary artery disease in HD and H Groups.

\begin{tabular}{|c|c|c|c|c|c|}
\hline Variables & & Group & Total & Total & p-value \\
\hline & & HD & $\mathrm{H}$ & & \\
\hline \multirow{3}{*}{ Coronary artery disease } & Yes & $218(23.42 \%)$ & $143(15.36 \%)$ & $361(38.78 \%)$ & \multirow{3}{*}{$<0.001$} \\
\hline & No & $238(25.56 \%)$ & $332(35.66 \%)$ & $570(61.22 \%)$ & \\
\hline & Total & 456(48.98) & $475(51.02 \%)$ & $931(100 \%)$ & \\
\hline \multirow{3}{*}{ Ischemia } & Yes & $76(13.33 \%)$ & $62(10.88 \%)$ & $138(24.21 \%)$ & \multirow{3}{*}{$<0.001$} \\
\hline & No & $162(28.42 \%)$ & $270(47.37 \%)$ & $432(75.79 \%)$ & \\
\hline & Total & $238(41.75 \%)$ & $332(58.25 \%)$ & $570(100 \%)$ & \\
\hline \multirow{3}{*}{ Myocardial infarction } & Yes & $26(6.02 \%)$ & $30(6.94 \%)$ & $56(12.96 \%)$ & \multirow{3}{*}{0.139} \\
\hline & No & $136(31.48)$ & $240(55.56 \%)$ & $376(87.04 \%)$ & \\
\hline & Total & $162(37.50 \%)$ & $270(62.50 \%)$ & $432(100 \%)$ & \\
\hline
\end{tabular}

Table-IV: Coronary artery disease in HD and H Groups according to symptoms of presentation.

\begin{tabular}{|c|c|c|c|c|c|c|}
\hline \multirow[t]{2}{*}{ Symptoms } & \multicolumn{2}{|l|}{ Variables } & \multicolumn{2}{|c|}{ Group } & \multirow[t]{2}{*}{ Total } & \multirow[t]{2}{*}{ p-value } \\
\hline & & & HD & $\mathbf{H}$ & & \\
\hline & \multirow[t]{3}{*}{ Coronary artery disease } & Yes & 73 & 26 & 99 & \multirow{3}{*}{0.654} \\
\hline & & No & 28 & 12 & 40 & \\
\hline & & Total & 101 & 38 & 139 & \\
\hline \multirow{6}{*}{ Typical Angina } & \multirow[t]{3}{*}{ Ischemia } & Yes & 13 & 4 & 17 & \multirow{3}{*}{0.443} \\
\hline & & No & 15 & 8 & 23 & \\
\hline & & Total & 28 & 12 & 40 & \\
\hline & \multirow[t]{3}{*}{ Myocardial infarction } & Yes & 5 & 2 & 7 & \multirow{3}{*}{0.679} \\
\hline & & No & 10 & 6 & 16 & \\
\hline & & Total & 15 & 8 & 23 & \\
\hline \multirow[t]{9}{*}{ Atypical Presentation } & \multirow[t]{3}{*}{ Coronary artery disease } & Yes & 145 & 117 & 262 & \multirow{3}{*}{$<0.001$} \\
\hline & & No & 210 & 320 & 530 & \\
\hline & & Total & 355 & 437 & 792 & \\
\hline & \multirow[t]{3}{*}{ Ischemia } & Yes & 62 & 59 & 121 & \multirow{3}{*}{0.003} \\
\hline & & No & 148 & 261 & 409 & \\
\hline & & Total & 210 & 320 & 530 & \\
\hline & \multirow[t]{3}{*}{ Myocardial infarction } & Yes & 23 & 26 & 49 & \multirow{3}{*}{0.095} \\
\hline & & No & 125 & 235 & 360 & \\
\hline & & Total & 148 & 261 & 409 & \\
\hline
\end{tabular}

\section{DISCUSSION}

In this retrospective analysis, prevalence of CAD was estimated in essential hypertensive (HTN) patients with and without diabetes mellitus (DM) by using SPECT cardiac
MIBI scan. Our study showed a statistically significant difference in prevalence of CAD between HD and H groups, prevalence being almost 1.5 times more in HD group than $\mathrm{H}$ group (47.8\% vs. $30.1 \%, \mathrm{p}<0.001)$. Difference in prevalence of ischemia was almost 2 times higher in HD group than $\mathrm{H}$ 
groups. This high prevalence of CAD in HD than $\mathrm{H}$ group highlights the importance of diabetes mellitus as a major risk factor for $\mathrm{CAD}$, as shown by different other research workers in their work correlating different CAD risk factors with the likelihood of CAD ${ }^{[6,7]}$. Diabetes mellitus has been found as an independent risk factor for $\mathrm{CAD}$, irrespective of the fact whether other risk factors are present or absent ${ }^{\left[{ }^{[8]}\right.}$ Our results are similar to those of Lacourciere et al ${ }^{[9]}$. They conducted MPS in 1116 hypertensive patients without known coronary artery disease (CAD), and found CAD in $28.9 \%$ of patients. In their study the prevalence of CAD was higher in hypertensive patients with diabetes mellitus (DM) than without diabetes mellitus ( $35.9 \%$ vs. $23.9 \%$; odds ratio, $1.79 ; 95 \%$ confidence interval, $1.38-2.33 ; \mathrm{p}<0.0001)$. Their reported prevalence is somewhat less than that of our study, and is most likely related to different set of population. Although many studies had been conducted to determine the prevalence of $\mathrm{CAD}$ in diabetic patients, only few studies are available which compare the prevalence of CAD in hypertensive subjects with and without diabetes mellitus. Reported prevalence of CAD in diabetic subjects in various studies markedly varies due to different set of population and criteria used by different researchers ${ }^{[10]}$.

In hypertensive subjects without diabetes mellitus, who are on adequate treatment, reported prevalence of CAD is almost similar to that of non-hypertensive subjects, as shown by Elhendy et al in their study. They compared the prevalence and extent of stress induced myocardial perfusion abnormalities in 350 patients without known CAD, including 146 hypertensive patients, by using dobutamine stress $99 \mathrm{mTc}$ myocardial perfusion SPECT imaging. They reported prevalence of CAD in hypertensive and non-hypertensive subjects to be $28 \%$ vs. $31 \%$ in patients with low, $38 \%$ vs. $33 \%$ in patients with intermediate and $60 \%$ vs. $58 \%$ in patients with high pretest probability of CAD, respectively. They found that treated HTN patients without known $\mathrm{CAD}$ have a similar prevalence and severity of myocardial perfusion abnormalities, compared with normotensive patients with similar clinical characteristics [11].

The risk of cardiovascular events in patients with diabetes is twofold to fourfold greater than individuals of same age and sex without diabetes ${ }^{[12]}$. Patients of hypertensive diabetes had a higher risk of cardiovascular events, the risk of myocardial infarction was 12.2 times greater and the risk of stroke was 6.1 times greater than non-diabetic hypertensive patients ${ }^{[13]}$.

In our study we found that prevalence of CAD in males was significantly higher than that in females of both HD and $\mathrm{H}$ groups. In males, prevalence was slightly higher in $\mathrm{HD}$ group than $\mathrm{H}$ group, while in females it was almost 2 times higher in $\mathrm{HD}$ group than that of $\mathrm{H}$ group. The results of study of Manfirini et al showed that women had more traditional risk factor of cardiovascular disease as compared to male counterparts and women also had greater risk of developing cardiovascular events than males ${ }^{[14]}$.

In our study, we found that prevalence of CAD was significantly higher in patient who presented with angina as compared to those with atypical presentation in both $\mathrm{HD}$ and $\mathrm{H}$ groups. In patients with typical presentation, we found almost similar prevalence of CAD in $\mathrm{HD}$ and $\mathrm{H}$ groups in males and females. Similar prevalence of CAD in patients with typical presentation in $\mathrm{HD}$ and $\mathrm{H}$ groups shows that when patient develops typical angina, then extent of prevalence is not dependent on the presence or absence of diabetes mellitus or gender. Observed almost 2 times higher prevalence of $\mathrm{CAD}$ in patients with atypical presentation of HD group than $\mathrm{H}$ group is due to blunt pain perception caused by autonomic neuropathy in diabetic subjects. As a result of this reduced pain perception, myocardial ischemia or infarction may go unrecognized, resulting in high rates of silent coronary events and events with atypical presentation. Other causes of more common atypical presentation in diabetics include increased pain threshold, increased $\beta$-endorphin levels, impairment of pain pathways, smaller ischemic regions in comparison with painful angina, psychological factors and transient platelet micro aggregates [15].

Nesto et al studied 50 consecutive patients with diabetes and 50 consecutive patients without diabetes (irrespective of hypertension), all with ischemia, on exercise. Tl scintigraphy and found that only 14 patients with diabetes compared with 34 patients without diabetes had angina during exertional ischemia. He concluded that absence of angina is an unreliable index of myocardial ischemia in diabetic patients with coronary artery disease ${ }^{[16]}$. Aslam et al ${ }^{[17]}$ conducted myocardial perfusion scintigraphy in 266 diabetic subjects who were either asymptomatic or having atypical presentation, and found CAD in $52.6 \%$ subjects (inducible ischemia in $40.6 \%$ and $\mathrm{MI}$ in $12 \%$ subjects). In totally asymptomatic subjects of their study, this prevalence of CAD was $46.1 \%$, while in other subjects with atypical presentation CAD was present in $61.4 \%$ subjects. Prior et al ${ }^{[18]}$ also found silent stress induced perfusion defects in diabetic patients, at a rate almost similar to that in patients with a history of chest pain. However, these two researchers did not separate the typical angina patients from patients with atypical chest pain.

In our study, we found that prevalence of CAD increases with increasing age in both HD and H groups. Prevalence of ischemia and MI behaved with a trend similar to that of CAD, i.e. prevalence increases with increasing age. We found that although prevalence of CAD increases with increasing age in both groups, this increase was more marked in $\mathrm{HD}$ group than $\mathrm{H}$ group. It is explainable on the basis that rate of atherosclerosis increases with increasing age, and progression of atherosclerosis is more rapid in patients with diabetes mellitus than those without diabetes ${ }^{[19]}$.

Our study documented that prevalence of CAD increases with increasing age in all the groups based on clinical presentation in both $\mathrm{HD}$ and $\mathrm{H}$ groups and is due to increasing rate of atherosclerosis as the age advances ${ }^{[20]}$. With the exception of HD subjects with age less than 36 years, prevalence of CAD was higher in patients with typical presentation than subjects with atypical presentation in all other subgroups 
based on age and clinical presentation in both HD and $\mathrm{H}$ groups. This study showed that there is no statistically significant difference in CAD prevalence between $\mathrm{HD}$ and $\mathrm{H}$ group patients who presented with typical presentation and have age between 36 and 50 years. This comparison could not be done in typical presentation patients with age greater than 65 years because there was no patient in $\mathrm{H}$ group of this category. In subgroup of patients who have atypical presentation, prevalence of CAD was higher in HD group than $\mathrm{H}$ group subjects of all ages and is explainable on the basis of blunt pain perception in diabetics. In subgroup of patients with age less than 36 years and typical presentation, number of patients was very small in both HD $(n=3)$ and $\mathrm{H}$ groups $(\mathrm{n}=4)$, and hence results should not be compared, although higher prevalence of CAD was noted in group $\mathrm{H}$ than HD group.

\section{CONCLUSION}

This study concludes that there is high prevalence of coronary artery disease in hypertensive subjects with diabetes mellitus (HD group) than those hypertensive patients without diabetes mellitus ( $\mathrm{H}$ group). Prevalence of CAD increases with increasing age and also male predominance. So, we recommend that further extensive studies are needed with larger study populations, preferably conducted at multiple centers to accurately find the prevalence of CAD in different subgroup of patients based on risk factors for CAD. Confirmation and correlation with other modalities like PTCA, CT angiography, MR angiography, etc. should also be done.

ACKNOWLEDGEMENT: None. CONFLICT OF INTEREST: None.

GRANT SUPPORT AND FINANCIAL DISCLOSURE: None.

\section{REFERENCES}

1. Pang Z, Wang J, Li S, Chen Y, Wang X, Li J. Diagnostic analysis of new quantitative parameters of lowdose dynamic myocardial perfusion imaging with CZT SPECT in the detection of suspected or known coronary artery disease. The International Journal of Cardiovascular Imaging. 2021;37(1):367-378. Doi:10.1007/s10554-020-01962-x

2. Venuraju SM, Lahiri A, Jeevarethinam A, Cohen M, Darko D, Nair D, et al. Duration of type 2 diabetes mellitus and systolic blood pressure as determinants of severity of coronary stenosis and adverse events in an asymptomatic diabetic population: PROCEED study. Cardiovascular Diabetology. 2019;18(1):1-9. Doi:10.1186/s12933-019-0855-8

3. Shen Y, Dai Y, Wang XQ, Zhang RY, Lu L, Ding FH, et al. Searching for optimal blood pressure targets in type 2 diabetic patients with coronary artery disease. Cardiovascular Diabetology. 2019;18(1):1-3. Doi:10.1186/s12933-019-0959-1
4. Curley D, Plaza BL, Shah AM, Botnar RM. Molecular imaging of cardiac remodelling after myocardial infarction. Basic Research in Cardiology. 2018;113(2):1-8. Doi:10.1007/s00395-018-0668-z

5. Hussain N, Parker MW, Henzlova MJ, Duvall WL. Stress-first myocardial perfusion imaging. Cardiology clinics. 2016;34(1):59-67. Doi:10.1016/j. ccl.2015.06.006

6. Al-Humaidi G, Sarikaya I, Elgazzar AH, Owunwanne A. Myocardial perfusion abnormalities in asymptomatic type 2 diabetic patients. Journal of the Saudi Heart Association. 2018;30(1):3-8. Doi:10.1016/j. jsha.2017.04.006

7. Green R, Cantoni V, Petretta M, Acampa W, Panico $\mathrm{M}$, Buongiorno $\mathrm{P}$, et al. Negative predictive value of stress myocardial perfusion imaging and coronary computed tomography angiography: a meta-analysis. Journal of Nuclear Cardiology. 2018;25(5):1588-1597. Doi:10.1007/s12350-017-0815-1

8. Gyldenkerne C, Olesen KK, Thrane PG, Madsen M, Thim T, Würtz M. Diabetes is not a risk factor for myocardial infarction in patients without coronary artery disease: A study from the Western Denmark Heart Registry. Diabetes and Vascular Disease Research. 2020;17(4):1479164120941809. Doi. org/10.1177/1479164120941809

9. Lacourcière Y, Côté C, Lefebvre J, Poirier L, Dumont M. Identifying which treated hypertensive patients without known coronary artery disease should be tested for the presence of myocardial ischemia by perfusion imaging. The Journal of Clinical Hypertension. 2007;9(12):921928.

10. Sheikh MS, Aljohani EM, Alrayes FH, Aldakhil AR. Hypertension and Coronary Heart Disease in Diabetic Patients: A Systematic Review. Archives of Pharmacy Practice. 2020;1:130-134.

11. Elhendy A, Schinkel AF, Van Domburg RT, Bax JJ, Poldermans D. Comparison of late outcome in patients with versus without angina pectoris having reversible perfusion abnormalities during dobutamine stress technetium-99m sestamibi single-photon emission computed tomography. The American Journal of Cardiology. 2003;91(3):264-268. Doi:10.1016/S00029149(02)03152-1

12. Patti G, Cavallari I, Andreotti F, Calabro P, Cirillo P, Denas G, et al. Prevention of atherothrombotic events in patients with diabetes mellitus: from antithrombotic therapies to new-generation glucose-lowering drugs. Nature Reviews Cardiology. 2019;16(2):113-130. Doi:10.1038/s41569-018-0080-2

13. Sousa AC, Jardim TV, Costa TO, Magalhães FG, Montelo MP, Souza WK, et al. Hypertensive diabetic patients: incidence of cardiovascular and renal outcomes in a historical cohort over 11 years. Diabetology \& Metabolic Syndrome. 2017;9(1):1-9. Doi:10.1186/ s13098-017-0296-Z 
14. Manfrini O, Yoon J, van der Schaar M, Kedev S, Vavlukis M. Sex differences in modifiable risk factors and severity of coronary artery disease. Journal of the American Heart Association. 2020;9(19):e017235. Doi:10.1161/JAHA.120.017235

15. Petrie JR, Guzik TJ, Touyz RM. Diabetes, hypertension, and cardiovascular disease: clinical insights and vascular mechanisms. Canadian Journal of Cardiology. 2018;34(5):575-584. Doi:10.1016/j.cjca.2017.12.005

16. Nesto RW, Phillips Rt, Kett Kg, Hill T, Perper E, Young E, Leland JR OS. Angina and exertional myocardial ischemia in diabetic and nondiabetic patients: assessment by exercise thallium scintigraphy. Annals of Internal Medicine. 1988;108(2):170-175. Doi:10.7326/0003-4819-108-2-170

17. Aslam MN, Afzal MS, Javad H, Imran MB, Sarfraz M, Irfanullah J. Role of Myocardial Perfusion Scintigraphy in Diabetics patients: detection of Myocardial Ischemia in asymptomatic subjects or those with atypical presentation. Pakistan Journal of Cardiology. 2004;15(1):3-11. Doi:10.3389/fendo.2018.00002

18. Prior JO, Monbaron D, Koehli M, Calcagni ML, Ruiz J, Delaloye AB. Prevalence of symptomatic and silent stress-induced perfusion defects in diabetic patients with suspected coronary artery disease referred for myocardial perfusion scintigraphy. European Journal of Nuclear Medicine and Molecular Imaging. 2005;32(1):60-69. Doi:10.1007/s00259-004-1591-0

19. Regassa LD, Tola A, Ayele Y. Prevalence of Cardiovascular Disease and Associated Factors Among Type 2 Diabetes Patients in Selected Hospitals of Harari Region, Eastern Ethiopia. Frontiers in Public Health. 2021:1057.

20. De Rosa S, Arcidiacono B, Chiefari E, Brunetti A, Indolfi C, Foti DP. Type 2 diabetes mellitus and cardiovascular disease: genetic and epigenetic links. Frontiers in Endocrinology. 2018;9:2. Doi:10.3389/ fendo.2018.00002

\section{Author's Contribution:}

Owais Bin Qadeer Gill: Conception and design, revising it critically for intellectual content, final approval.

Talal Abdul Rehman: Acquisition of data, interpretation of data, final approval.

Hafiz Amjad Hussain: Conceived and designed the analysis. Proof reading of the manuscript.

Muhammed Shahzad Afzal: Acquisition of data, analysis of data, drafting the article, final approval.
Submitted for publication: 08-08-2021

Accepted after revision: 28-02-2022 